\title{
AS MEDIDAS PROVISÓRIAS NA CORTE INTERNACIONAL DE JUSTIÇA: Caso LaGrand (Alemanha v. Estados Unidos da América).
}

\author{
Diego Oliveira Telles da Silva ${ }^{1}$
}

\begin{abstract}
ÍNDICE: INTRODUÇÃO; 1 CASO LAGRAND; 2 PRESSUPOSTOS E FINALIADE; 3 DA NÃO ANTECIPAÇÃO DE MÉRITO E OUTRAS QUESTÕES QUANTO A FINALIDADE; 4 OBRIGATORIEDADE; 5 CONCLUSÃO; 6 REFERÊNCIAS.
\end{abstract}

\section{RESUMO}

O presente estudo busca analisar o instituto das medidas provisórias a partir das problemáticas e discussões originadas no caso LaGrand na Corte Internacional de Justiça. Para tanto, utilizou-se preceitos gerais aplicáveis ao caso, bem como, fundamentos de base doutrinária sobre o tema. Em linhas conclusivas, verificou-se a existência de uma problemática acerca da efetividade das decisões da Corte Internacional de Justiça, pois, mesmo que se reconheça o caráter obrigatório das medidas provisórias, seus meios de implementação carecem de força substancial, remanescendo hipóteses de incumprimento sem quaisquer tipos de sanções, fato pelo qual, necessita-se de implementação de vias diversas impositivas para buscar uma possível efetividade, onde haja o gravame de responsabilização nas hipóteses de descumprimento.

Palavras-Chave: Direito Internacional. LaGrand. Medidas Provisórias. Corte Internacional de Justiça.

\footnotetext{
${ }^{1}$ Advogado; Pós-graduado em Direito Tributário pela FGV-Rio; e Mestrando em Direito Fiscal pela Universidade de Coimbra.
} 


\section{INTRODUÇÃO}

O caso LaGrand trouxe uma alteração de paradigma na jurisprudência da Corte de Internacional de Justiça, ao ponto que, ficara reconhecida o caráter da obrigatoriedade das mediadas provisórias, afastando assim, o anterior caráter indicativo.

Embora a obrigatoriedade seja a característica de mais destaque no caso LaGrand, não se restou como a única abordada, isto é, identifica-se a discussão do instituto das medidas provisórias em uma acepção ampla, razões pelas quais, esse caso toma relevância para o fim objetivado por este estudo.

Dessa forma, o presente paper objetivará a análise do instituto das medidas provisórias a partir das problemáticas e discussões originadas no caso LaGrand. Outrossim, para atingir esse propósito, o método utilizado será através da base teórica e doutrinária sobre o tema, buscando os preceitos gerais aplicáveis.

Por fim, o ponto de partida será da análise da discussão do caso LaGrand, todavia, destaca-se que a apreciação desse litígio será focada quanto ao referente às medidas provisórias, não aprofundado quanto as demais questões; seguido pela análise dos pressupostos, finalidades e características das medidas provisórias; e ao fim, será exposta a conclusão atingida.

\section{CASO LAGRAND}

O caso LaGrand é consubstanciado na reclamação por violação do Tratado de Viena sobre Relações Consulares (TVRC), assim proposto pela República Federativa da Alemanha em face aos Estados Unidos da América, tratado esse, ratificado por ambos ${ }^{2}$.

No mais, a problemática se perfaz no julgamento de dois cidadãos alemães (Karl LaGrand e Walter LaGrand) perante a Superior Court of Pima County, no Arizona, em que se concluiu pela condenação de ambos à pena de morte pela prática de assassinato de primeiro grau, tentativa de assassinato de primeiro grau, tentativa de assalto à mão armada e sequestro, em 14 de dezembro de 1984.

\footnotetext{
2 INTERNATIONAL COURT OF JUSTICE. Reports of Judgments, Advisory Opinions and Orders. LaGrand Case (Germany V. United States of America). Judgment Of 27 June 2001, paras. 1 e 15.
} 
Com inconformismo pela condenação supra, os irmãos LaGrand apresentaram diversos recursos e pedidos de revisões à Corte Estadual do Arizona, à Suprema Corte do Arizona e à Suprema Corte dos Estados Unidos, contudo, nenhum desses obtivera êxito ${ }^{3}$.

Por sua vez, em 1992, os referidos sentenciados tomaram conhecimento do direito de comunicação e assistência consular, assim inserto no art. 36 , parágrafo $1^{\circ}$, al. a) e b) do $\mathrm{TVRC}^{4}$, razões pelas quais, impetraram de Habeas Corpus na Corte Distrital do Estados Unidos do Distrito do Arizona, sob a alegação de violação do devido processo legal, visto que, as autoridades americanas restaram-se omissas no dever de informar tais direitos 5 .

Embora a existência da violação do devido processo legal no momento da apreensão dos sentenciados, ficou-se reconhecida pelos tribunais acionados a configuração da preclusão do direito reclamado, visto que, a alegação deveria ter sido exposta na primeira oportunidade de manifestação ${ }^{6}$.

Diante de tais fatos, a via recursal do processo discutido restou-se exaurida, e, por consequência, a Suprema Corte do Arizona decidiu pelo agendamento da execução da pena imposta, isto é, a pena de morte, sendo ao dia 24 de fevereiro de 1999 para Karl LaGrand em, e em 03 março de 1999 para Walter LaGrand.

Menciona-se ainda que, desde 1992, com o conhecimento da situação dos irmãos LaGrand, o Estado Alemão também promoveu diversos atos para reverter a condenação de pena de morte, utilizando-se dos mais diversos meios diplomáticos, todavia, assim como os resultados obtidos pelos meios legais utilizados pelos irmãos, a Alemanha também não obteve resposta favorável ${ }^{7}$.

Com o cumprimento da execução de Karl LaGrand, em 02 de março de 1999, o Estado Alemão apresentou petição à Corte Internacional de Justiça sobre a violação do TVRC por parte dos Estados Unidos da América, fundamentando a legitimidade da corte

\footnotetext{
${ }^{3}$ Idem, para. 20.

${ }^{4}$ Idem, para. 13 e 22.

5 BARROS, Napoleão Lucília. Soberania, Direitos Humanos e os Poderes de Pronúncia da Corte Internacional de Justiça a partir dos Casos LaGrand e Avena. Dissertação de Mestrado em Direito Internacional Público apresentada à Faculdade de Direito da Universidade de Coimbra. Coimbra. 2008, pgs. 98 e 99.

${ }^{6}$ INTERNATIONAL COURT OF JUSTICE. Reports of Judgments... paras. 22 e 23.

${ }^{7}$ Idem, paras. 26 e 27.
} 
no art. $36, \S 1^{\circ}$ do Estatuto da $\mathrm{CIJ}^{8}$ e no art. $1^{\circ}$ do Protocolo Facultativo do TVRC relativo à Resolução Obrigatória de Disputas ${ }^{9}$, tratados em que ambas as partes são signatárias ${ }^{10}$.

Dentre os diversos pedidos realizados pelo Estado Alemão, pode-se destacar a restauração do status quo de Walter LaGrand, isto é, ao momento prévio da detenção, do trâmite processual e da condenação, bem como, requereu, como medida interina, a aplicação de medidas pela CIJ para a proteção da demanda, sem mais especificações ${ }^{11} 12$.

Diante a urgência do caso, ao dia da execução de Walter LaGrand, em 03 de março de 1999, a CIJ, fundamentada no art. 75, parágrafo 1 , de seu regimento interno ${ }^{13}$, exarou ordem de medida interina proprio motu, isto é, sem o prévio contraditório do demandado ${ }^{14}$, para que fosse suspensa a execução de Walter LaGrand até decisão definitiva da presente demanda, e que o governo dos Estados Unidos da América deveria transmitir essa ordem ao governador do Estado do Arizona ${ }^{15}$. Vale mencionar ainda que, essa fora a primeira vez que a CIJ proferiu medidas provisórias proprio motu, conforme a normativa de seu regimento interno ${ }^{16}$.

Todavia, apesar da ordem proferida pela CIJ, as autoridades americanas deram continuidade com a execução de Walter LaGrand, informando a essa corte que, embora todas as medidas tivessem sido aplicadas para contribuir com o cumprimento da decisão, o curto espaço de tempo entre a data de proferimento da ordem e a execução

\footnotetext{
$8<[\ldots]$ The jurisdiction of the Court comprises all cases which the parties refer to it and all matters specially provided for in the Charter of the United Nations or in treaties and conventions in force.> INTERNATIONAL COURT OF JUSTICE. Statute of The International Court of Justice. Disponível em: $<$ http://www.icj-cij.org/en/statute>. 10 de março de 2018.

$9<[\ldots]$ Disputes arising out of the interpretation or application of the Convention shall lie within the compulsory jurisdiction of the International Court of Justice and may accordingly be brought before the Court by an application made by any party to the dispute being a Party to the present Protocol.> UNITED NATIONS, Treaty Series, vol. 596, 2005, p. 487.

10 INTERNATIONAL COURT OF JUSTICE. Application, Instituting Proceedings, LaGrand Case (Germany V. United States of America), 2 March 1999, paras. 11-13.

$11<17$. The Federal Republic of Germany requests the Court to indicate provisional measures of protection, as set forth in a separate request filed concurrently with this Application.> idem, para. 17.

${ }^{12}$ Idem, paras. 15-17.

${ }^{13}<$ Article 75. 1. The Court may at any time decide to examine proprio motu whether the circumstances of the case require the indication of provisional measures which ought to be taken or complied with by any or all of the parties $>$. INTERNATIONAL COURT OF JUSTICE. Rules of Court (1978). Adopted on 14 april 1978 and entered into force on 1 july 1978. Disponível em: $<$ http://www.icj-cij.org/en/rules $>$. 11 de março de 2018.

${ }^{14}$ MENNECKE, Martin; TAMS, Christian. The Right to Consular Assistance Under International Law: The LaGrand Case Before the International Court of Justice, German Tearbook of International Law, vol. 42, 1999, p. 195.

${ }^{15}$ INTERNATIONAL COURT OF JUSTICE. Reports of Judgments, Advisory Opinions and Orders. LaGrand Case (Germany V. United States of America), Order of 3 March 1999, paras. 22 e 29.

${ }^{16}$ BARROS, Op. Cit., pg. 104 e 105.
} 
(ambas em 03 de março de 1993); outrossim, ainda fora alegado que as medidas provisórias carecem de obrigatoriedade no seu cumprimento ${ }^{17}$.

Conforme a alegação realizada pelos Estados Unidos e as condições visualizadas pela Corte para proferir as medidas provisórias aplicadas no caso em comento, bem como, a finalidade dessas, passa-se a analisar os elementos que compõem o instituto objeto de análise desse estudo, para assim verificar a validade da decisão da Corte e a plausibilidade da defesa apresentada.

\section{PRESSUPOSTOS E FINALIDADE}

Como primeiro elemento a ser analisado das medidas provisórias, destacamse seus pressupostos, isto é, suas condições sine qua non de validade, que assim expressam, cumulativamente com sua finalidade, seus motivos de existência. Nesse sentido, elenca-se os seguintes pressupostos das medidas provisórias: a competência prima facie; a urgência na necessidade de apreciação da causa pela Corte; e a existência de risco de prejuízo irreparável. Destaca-se ainda, a existência de direito prima facie como pressuposto, embora sua inserção não seja uníssona na doutrina.

A competência perfaz um pressuposto direcionado à processualística pertinente às medidas provisórias, no qual, em sua ausência, implicará na própria validade da decisão ${ }^{18}$. Outrossim, para a compreensão desse pressuposto, necessita-se fazer a distinção de suas duas espécies: a competência para decidir sobre a matéria - processo

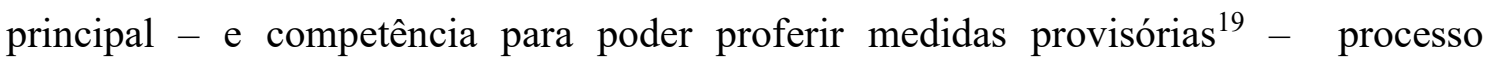
incidental, dependente do principal -.

Esse fracionamento recai pelo próprio grau de dependência entre o processo incidental (requerimento de medidas provisórias) e o processo principal, visto que, o objeto de apreciação daquele, deve ser conforme ao objeto demandado desse. Para um

\footnotetext{
${ }^{17}$ INTERNATIONAL COURT OF JUSTICE. Reports of Judgments... Judgment Of 27 June 2001, paras. 95 e 96.

18 BERNHARDT, Rudolf. Interim Measures Indicated by International Courts. Berlin; New York: Springer-Verlag, 1996, p. 16.

${ }^{19}$ Idem, Op. Cit., p. 18.
} 
direito ser protegido pela ordem de medidas provisórias, não basta dele o Estado ser titular, o mesmo deve ser objeto de uma das pretensões no processo principal ${ }^{20}$.

Por definição, as medidas provisórias possuem o escopo de preservar ou anular uma violenta ou súbita alteração do status quo ${ }^{21}$, garantindo o direito de ambas as partes e que a decisão final não seja prejudicada pela perda do objeto. Diante esse caráter, perfazem-se como meios de garantia ao exercício das funções institucionais da CIJ, assegurando a boa administração da justiça, por preservar a utilidade da decisão, obstando quaisquer prejuízos ocasionados por eventual morosidade ${ }^{22}$. Razões pelais quais, essas medidas apenas têm sentido em estrita conexão com o processo principal, em que a CIJ só poderá considerar-se competente para as determinar, se entender que goza de competência para julgar o objeto principal ${ }^{23}$.

No mais, quanto a preservação equitativa dos direitos das partes, importante ressaltar que, as medidas provisórias não visam apenas proteger os direitos de quem as requereu, as mesmas devem ser equilibradas no sentido de atender à posição de cada parte, fato pelo qual, conforme o art. 75, n. ${ }^{\circ} 2$ do Regulamento da CIJ, a Corte poderá determinar medidas que são no todo ou em parte diferentes daquelas solicitadas, dirigidas ao requerido ou ao próprio requerente ${ }^{24}$.

Quanto à competência sobre para decidir sobre a matéria constante no processo principal, diante a soberania dos Estados, necessita-se o reconhecimento por parte desses acerca da competência da CIJ como órgão de solução pacífica de conflitos internacionais. O referido reconhecimento é dado pelo aceite da denominada "cláusula facultativa de competência obrigatória" ${ }^{25}$, assim inserta no art. 36, item n. ${ }^{\circ} 2$ do Estatuto da CIJ.

Com o reconhecimento da cláusula supramencionada, o Estado fica subordinado à competência obrigatória da CIJ, não necessitando de autorização específica

\footnotetext{
${ }^{20}$ DANIELE, Luigi. Le Misure Cautelari nel Processo Dinanzi alla Corte Internazionale di Giustizia, Milano, Guiffré, 1993, p. 73.

${ }^{21}$ COLLINS, Lauwrence. Provisional and Protective Measures in International Litigation, Recueil des Cours de l'Académie de Droit International - RCADI, vol. III, 1992, p. 232.

${ }^{22}$ MÜLLER, Daniel. Chronique de la CIJ. Revue Qudicoise de Droit International - RQDI, vol. 19.1, 2006, p. 251-252.

${ }^{23}$ PEREIRA, Op. Cit., p. 76.

${ }^{24}$ Idem, p. 47.

${ }^{25}$ PEREIRA, Maria de Assunção do Vale. As Medidas Provisórias na Jurisprudência Recente do Tribunal Internacional de Justiça. Boletim da Faculdade de Direito - Universidade de Coimbra, STVDIA IVRIDICA 35, Coimbra: Coimbra Editora, 1998, p. 75.
} 
para cada conflito suscitado, todavia, esse reconhecimento deve ser feito de via expressa, não bastando esse Estado ser membro da ONU e signatário do Estatuto da $\mathrm{CIJ}^{26}$.

A cláusula facultativa de competência obrigatória toma um caráter de generalidade, pois submete todas controvérsias referentes a qualquer questão de direito internacional à CIJ. Todavia, a problemática no caso LaGrand se perfaz pela ausência de reconhecimento dessa cláusula por parte dos Estados Unidos, fato que implicaria na própria competência para proferir medidas provisórias, diante a situação de dependência.

Apesar da ausência de reconhecimento supra, destaca-se ainda que, a cláusula supramencionada não se resta como único meio de atribuir a competência da CIJ sobre matérias relativas a determinados Estados, conforme assim assinalado pela Alemanha em seus memoriais ${ }^{27}$, elencando-se à ratificação do Protocolo Facultativo do TVRC por parte dos Estados Unidos.

A normativa inserta no artigo I desse protocolo, toma um caráter de reconhecimento de competência para solução de controvérsias específicas, pois, dispõe que as partes-membros desse protocolo se submetem à competência obrigatória da CIJ quanto às controvérsias decorrentes da interpretação ou aplicação do TVRC. Fato pelo qual, de forma expressa, impõe-se a competência da CIJ aos Estados Unidos pela prática de ato volitivo ao reconhecimento dessa cláusula, embora específica, mas aplicável ao caso LaGrand ${ }^{28}$.

Nesse sentido, apesar do não reconhecimento da cláusula facultativa de competência obrigatória da CIJ, os Estados Unidos reconheceram a competência dessa Corte para julgar as demandas pertinentes à aplicação e interpretação do TVRC, diante a ratificação do Protocolo Facultativo desse tratado, firmando assim, a competência da Corte para julgar o caso LaGrand. No mais, diante o firmamento da competência sobre a demanda principal, torna-se inerente a competência da Corte à determinação de medidas

\footnotetext{
${ }^{26}$ HUSEK, Carlos Roberto. Curso de Direito Internacional Público, 14a edição, São Paulo: LTr, 2017, p. 330-331.

${ }^{27}$ INTERNATIONAL COURT OF JUSTICE. LaGrand Case (Germany v. United States of America), Memorial of the Federal Republic of Germany, Vol. 1, 1999, para. 3.10.

${ }^{28}$ INTERNATIONAL COURT OF JUSTICE. Reports of Judgments, Advisory Opinions and Orders. LaGrand Case (Germany V. United States of America), Order of 3 March 1999, para. $48 ; 64$.
} 
provisórias - competência incidental - não se restando necessário o reconhecimento específico pelas partes, por força do art. 41 do Estatuto da $\mathrm{CIJ}^{29}$.

Ainda quanto ao reconhecimento de competência, é válido destacar a doutrina do forum prorogatum, assim fundamentada na manifestação informal do consentimento $^{30}$. Por essa doutrina, cria-se uma possibilidade de reconhecimento de competência independentemente do reconhecimento de cláusula facultativa, geral ou específica, de competência obrigatória.

Entretanto, para que ocorra o reconhecimento por essa metodologia, cabe aferir a existência de manifestação não solene do consentimento do Estado após ao início do processo, isto é, caso o Estado pratique atos que consubstanciem uma aderência à competência da CIJ, desnecessária seria a existência de reconhecimento formal ${ }^{31}$.

Posto isso, para preencher o pressuposto da competência, a Corte não necessita realizar uma apreciação exaustiva desse tema, basta-se identificar uma competência prima facie para julgar a matéria pertinente ao litígio apresentado.

A competência prima facie, embora utilizada como fundamentação para a determinação de medidas provisórias pela CIJ, a mesma carece de uma definição precisa. No entanto, conforme se manifesta a doutrina, é possível extrair o uso de critérios negativos (manifesta incompetência) e positivos (base sobre a qual a competência pode se manifestar) a partir de decisões pretéritas ${ }^{32}$.

Conforme o entendimento de Rucz, o primeiro critério pode ser verificado no caso Fisheries Jurisdiction, em que a competência prima facie é fundamentada pela ausência de manifesta incompetência sobre a matéria a ser julgada pela Corte ${ }^{33}$. Por sua vez, o critério positivo é verificado nos casos sucessores ao supramencionado, assim partindo da análise sumária da aptidão de um determinado título para fundamentar a

\footnotetext{
${ }^{29}$ BRIGGS, Hebert. La compétence incidente de la Cour internationale de Justice en tant que compétence obligatoire, Revue Générale de Droit International Public - RGDIP, 1960, p. 266 e ss.

${ }^{30}$ MACHADO, Jónatas E. M., Direito Internacional: Do paradigma clássico ao pós-11 de setembro, $3^{\circ}$ Edição, Coimbra: Coimbra Editora, 2006, p. 631.

${ }^{31}$ TRILWAY, Hugh. The law and procedure of the Internaional Court of Justice, 1960-1989, 72, The British Yearbook of International Law (Mark. W. Janis, Carolyn Evans, eds.), The Hague, 1999, p. 549-ss. ${ }^{32}$ LABOUZ, Marie-Françoise. Affaire des Activités Militaires et Paramilitaires au Nicaragua et Contre Celui-Ci (Nicaragua c. Etats-Unis D'amérique): Ordonnance de la Cour Internationale de justice du 10 mai 1984 en indication de mesures conservatoires, Annuaire Français de Droit Internacional - AFDI, 1984, p. 341-342.

33 RUCZ, Claude. L'indication de mesures conservatoires par la Cour Internationale de Justice dans L'affaire des militaires et paramilitaires au Nicaragua et contre celi-ci, Revue Générale de Droit International Public - RGDIP, 1985, n. ${ }^{\circ}$ 1, p. 83-111.
} 
conclusão por uma competência possível ${ }^{34}$, título no qual, ao que se refere o caso LaGrand, perfaz-se na figura do Protocolo Facultativo do TVRC ${ }^{35}$, em que há a aderência de cláusula acerca da competência da Corte para solucionar os litígios derivados desse tratado.

No mais, a apreciação da competência ainda poderá ser menos rigorosa diante a urgência e necessidade do caso, como aqueles em que se verifica um iminente risco de prejuízo irreversível a direitos da ação principal ${ }^{36}$, assim caracterizados pela impossibilidade de retorno ao status quo, seja em face à lei ou a questões de fato ${ }^{37}$.

Deve-se entender que, a urgência e o risco de prejuízo irreparável aos direitos questionados na ação principal não suprimem a necessidade da identificação de competência prima facie, isto é, todos os pressupostos devem estar presentes na demanda para possibilitar a ordem de medidas provisórias, bem como, a compatibilidade do objeto entre o requerimento incidental e o principal.

Quanto ao risco irreparável de dano, o mesmo deve ser apontado pelo Estado requerente da ordem de medida provisória, por força do art. 73, n. $^{\circ} 2$ do Regulamento da CIJ, expondo as possíveis consequências da hipótese de indeferimento do pedido, sendo assim, um importante fator de ponderação na apreciação do requerimento pela CIJ.

Sob a ótica do artigo supramencionado, o Estado Alemão, em seu requerimento de medidas provisórias, expôs o risco irreparável de dano a partir da iminência da execução da pena de morte de seu nacional, assim aplicada pelo demandado, outrossim, o direito em risco na presente questão, isto é, a vida, tornar-se-ia impossibilitada de retornar ao status quo ante em momento ulterior, razões pelas quais, justificaria a ordem pleiteada.

Diante as próprias justificativas do requerimento de medidas provisórias, pode-se perceber o grau de dependência com o direito pleiteado na demanda principal, visto que, pretende-se salvaguardar o pedido de suspensão da execução da pena de morte

\footnotetext{
34 PEREIRA, Op. Cit, p. 84.

35 INTERNATIONAL COURT OF JUSTICE. Reports of Judgments, Advisory Opinions and Orders. LaGrand Case (Germany V. United States of America), Order of 3 March 1999, para. 13-18.

${ }^{36}$ Idem, p. 84-85.

${ }^{37}$ MIRON, Alina; SUZINEAU, Simon; FARCHAKH-FOURET, Loubna; CAICEDO, Jose Joaquin. La Cour Internationale de Justice. Revue Qudicoise de Droit International - RQDI, vol. 20.1, 2007, p. 240.
} 
de Walter LaGrand. E ainda, na hipótese de indeferimento do pedido da aplicação das medidas, perder-se-ia um dos objetos pleiteados de apreciação na decisão final.

Por sua vez, a urgência, pressuposto indissociável ao risco de prejuízo irreparável, consagra-se através do caráter prioritário dado à apreciação dos requerimentos de aplicação de medidas provisórias inserto no art. 74 do Regulamento da CIJ. Quanto a esse pressuposto na demanda objeto de análise deste estudo, o mesmo é verificado no tempo entre o protocolo do pedido realizado pelo Estado Alemão, em 02 de março de 1999, e a data da execução da pena de morte de Walter LaGrand, em 03 de março de 1999, razões pelas quais, na ausência de uma apreciação imediata, tonar-se-ia sem utilidade a decisão final e a decisão sobre a aplicação dessas medidas.

Pela propositura da demanda em dia anterior à data da execução, pode-se perceber que o Estado Alemão também contribuiu para a problemática pertinente à urgência, pois o mesmo, inclusive, poderia ter feito o requerimento em data prévia à execução de Karl LaGrand. Embora a morosidade do Estado Alemão tenha colocado a Corte em uma posição delicada, conforme afirmam os juízes Oda e Schwebel em suas declarações ${ }^{38}$, o fato não trouxe prejuízos ao deferimento das medidas provisórias pleiteadas.

Por fim, embora não seja referenciado na totalidade das decisões da Corte, tão pouco seja apresentado como pressuposto por parte da doutrina, a existência de direito prima facie na demanda principal ganha destaque por já sido motivo de indeferimento por sua ausência, conforme o caso Great Belt, em que a Finlândia teve seu requerimento indeferido por não demonstrar a possibilidade da existência do direito reivindicado como objeto principal ${ }^{39}$.

A verificação desse elemento como pressuposto para pronúncia das medidas provisórias decorre de uma coerência a partir da possibilidade jurídica do pedido na demanda principal, visto que, esse instrumento poderia ser utilizável para obter, mesmo

\footnotetext{
${ }^{38}$ INTERNATIONAL COURT OF JUSTICE. LaGrand Case (Germany V. United States of America), Declaration of Judge Oda, 3 March 1999; INTERNATIONAL COURT OF JUSTICE. LaGrand Case (Germany V. United States of America), Declaration of Judge Schwebel, 3 March 1999;

${ }^{39}$ INTERNATIONAL COURT OF JUSTICE. Reports of Judgments, Advisory Opinions and Orders Case, Concerning Passage Through the Great Belt (Finland V. Denmark), Request for the Indication of Provisional Measures Order of 29 July 1991, 1991, para. 21; 38.
} 
que provisoriamente, a proteção de pretensões que jamais pudessem ser objeto de proteção através de uma sentença da Corte ${ }^{40}$.

Nesse sentido, diante a fase de pré-julgamento da demanda, requeresse uma tão somente visualização de indícios de direito, não sendo necessário uma apreciação exaustiva do fundo. Outrossim, apesar de carecer da exposição do convencimento da existência de direito prima facie nas decisões positivas de medidas provisórias, como o próprio caso LaGrand, a jurisprudência da Corte toma um rumo de negar o deferimento quando não identificado esse pressuposto ${ }^{41}$.

Quanto ao pressuposto do direito prima facie no caso LaGrand, embora não expresso no momento da ordem de medidas provisórias, o mesmo é de passível visualização diante a previsão do direito de comunicação consular inserto no art. 36 , parágrafo $1^{\circ}$, al. b) do TVRC, o qual fora negado.

\section{DA NÃO ANTECIPAÇÃO DE MÉRITO E OUTRAS QUESTÕES QUANTO A FINALIDADE}

A análise da respectiva característica dar-se-á ao seu destaque pela Corte no julgamento do caso LaGrand, sendo assim expressamente referenciado quanto a discussão sobre as medidas provisórias ${ }^{42}$. Nesse sentido, a partir de um viés negativo da acepção das medidas provisórias, entende-se que a análise aplicável deve ser sumária, impedindo assim, que a Corte, nesta fase de pré-julgamento, antecipe sua decisão de mérito ou limite a apreciação do objeto da demanda principal ${ }^{43}$. De forma substancial, analisa-se o escopo do pedido pleiteado pelo Estado requerente, isto é, busca-se a identificação da medida apenas como meio de assegurar o direito discutido na demanda principal, seja criando obstáculos para a continuação ou impedir que haja prática de atos ilícitos ${ }^{44}$.

\footnotetext{
${ }^{40}$ DANIELE, Op. Cit., p. 78.

${ }^{41}$ PEREIRA, Op. Cit., p. 166-167.

${ }^{42}$ INTERNATIONAL COURT OF JUSTICE. Reports of Judgments, Advisory Opinions and Orders. LaGrand Case (Germany V. United States of America), Order of 3 March 1999, 1999, para. 27.

${ }^{43}$ PEREIRA, Op. Cit., p. 155-162.

${ }^{44}$ VILlANI, Ugo. Tema di Indicazione di Misure Cautelari da Parte della Corte Internazionale di Giustizia, Rivista di Diritto Internazionale - RDI, vol. LVII, p. 673.
} 
Essa limitação é derivada da própria finalidade das medidas provisórias, qual seja, salvaguardar a utilidade da decisão, que assim se efetivará através de meios garantidores do objeto discutido da demanda principal, impedindo o desfazimento desse e, consequentemente, eventuais prejuízos à apreciação do mérito. Nesse sentido, as medidas provisórias têm o condão de proteger o direito discutido até a análise exaustiva da demanda, assim realizada na fase de sentença - decisão definitiva -.

Menciona-se ainda que, a identicidade entre os pedidos no requerimento de medidas provisórias e na demanda principal não é causa suficiente para o indeferimento daquelas, como assim já se prevaleceu a partir de um entendimento generalizado pelo indeferimento do pedido de medida provisória no caso Chorzow Factory, onde pleiteouse a medida com o fim de obter antecipação de indenização ${ }^{45}$.

Dessa forma, deve-se atentar a adequação do pedido requerido com finalidade das medidas provisórias, essas quais, conforme já mencionadas, buscam a preservação ou anulação de alteração ilícita do status quo, que, por consequência, reflete na manutenção da utilidade da sentença, pois não torna vazia a apreciação posterior do mérito por perda do objeto.

Ao que se refere o caso LaGrand, pôde-se identificar o enquadramento do pedido como medida de preservação do status quo, diante o iminente risco de alteração desse por um viés ilícito, agravado de irreversibilidade, visto que, trata-se do direito à vida face a execução de pena de morte originada de um processo eivado de ilicitude, diante o descumprimento, por parte dos Estados Unidos, do direito à comunicação consular.

\section{OBRIGATORIEDADE}

A contestação da obrigatoriedade das medidas provisórias é derivada de uma dualidade de posições doutrinárias sobre esse tema, havendo, de um lado, a tese de que essas medidas não possuem caráter vinculativo com seus destinatários; e de outro,

\footnotetext{
${ }^{45}$ SZTUCKI, Jerzy. Interim Measures in the Hague Court: An Attempt at a Scrutiny. Deventer: Kluwer Law and Taxation Publishers, 1983, p. 93.
} 
defende-se que a indicação de medidas resulta em uma obrigação jurídica, vinculando os seus destinatários ${ }^{46}$.

A primeira tese, é assim sustentada pela própria textual do parágrafo $1^{\circ}$, art. 41 do Estatuto da CIJ em inglês, atribuindo às medidas em um mero caráter de recomendação, não expressando ordem ou um dever, diante os termos insertos: "indicate" e "ought to be taken" 47 . Todavia, encontra-se divergência na comparação do texto inglês com o texto em francês, visto que, nesse último, inclina-se à ideia de obrigação, por utilizar a expressão "doivent être prises".

Quanto essa divergência entre versões, Sztucki explica que o texto francês é que deve ser tomado como original, cujos termos se mantiveram ao longo da maior parte dos trabalhos conducentes à redação do Estatuto, por sua vez, a versão inglesa teria sido uma tradução e adaptação, na qual, por hesitação, levou-se à utilização de "ought to be taken" ao em vez de "must be taken" 48.

Apesar da colocação supra, a discussão sobre a vinculação das medidas provisórias em face aos seus destinatários é originada desde o Estatuto da Corte Permanente de Justiça Internacional, diante a identicidade do art. 41 com o ulterior Estatuto da CIJ. Dentre os que tratavam desta temática, à época da CPJI, prevalecia-se a tese da não obrigatoriedade, sendo a doutrina praticamente unânime ${ }^{49}$, contudo, ao tempo da CIJ, verificou-se uma aproximação do caráter vinculativo ${ }^{50}$.

No mais, o próprio desenvolvimento da normativa da CPJI contribuiu à força da tese de não vinculação, conforme o travaux préparatoires de 1922, qual indicava essa característica às medidas provisórias ${ }^{51}$, assim consubstanciada pela recusa da proposta de Raul Fernandes, a qual constava, de forma expressa, o caráter imperativo dessas medidas,

\footnotetext{
${ }^{46}$ PEREIRA, Op. Cit., p. 282.

${ }^{47}$ HELLBECK, Eckhard. Provisional Measures of the International Court of Justice - Are They Binding Note, ASILS INT'L L.J., vol. 9, 1985, p. 169.

48 SZTUCKI, Jerzy. Interim Measures in the Hague Court: An Attempt at a Scrutiny. Deventer: Kluwer Law and Taxation Publishers, 1983, p. 264.

49 HAMBRO, Edvard. The Binding Character of Provisional Measures of Protection Indicated by the International Court of Justice, in Rechtsfragen der internationalen organization, Festschrift für Hans Wehberg zu seinem 70, Geburtstag, Herausgegeben von Walter Schatzel und Hans-Jürgen Schlochauer, Frankfur am Mai, Vitorio Klostermann, 1956, p. 164.

${ }^{50}$ SZTUCKI, Op. Cit., pg. 294.

${ }^{51}$ BERNHARDT, Op. Cit., pg. 28.
} 
bem como, em atribui-las um apoio por sanções, a fim de trazer efetividade às suas aplicações $^{52}$.

Destarte, outro fato que corroborava para a tese de não vinculação, é a forma de aplicação dessas medidas, isto é, por despacho diante a competência exclusiva do Presidente da Corte, sujeito impedido de proferir acórdãos, nos termos do art. 74, item n. ${ }^{\circ}$ 4 do Regulamento da CIJ. Essa problemática dos despachos é derivada da declaração da CPIJ em Affaire des Zones Franches, na qual expressou a carência de obrigatoriedade e definitividade dos despachos, embora não tenha havido abordagem direta aos despachos de medidas provisórias ${ }^{53}$.

Diversos outros fatores fundamentavam essa tese da não vinculação, como aquelas ligadas à ausência de meio de efetivação das medidas provisórias, a contrário modo de previsão expressa às sentenças definitivas da CIJ, nos termos do art. 94, da Carta das Nações Unidas, podendo-se recorrer ao Conselho de Segurança para que este, julgando necessário, faça recomendações ou tome medidas para o cumprimento da sentença ${ }^{54}$. Todavia, vale mencionar que, o art. 94 é expresso em mencionar "decisões", não a especificando.

Nesse sentido, prevaleceu-se a tese da não vinculação durante grande parte da existência da CPJI, restando-se apenas a possibilidade de vinculação derivada do pacta sunt servanda, isto é, conforme determinação em tratados internacionais para a solução pacífica de conflitos ${ }^{55}$. Entretanto, apesar da predominância, a mesma começara a ser confrontada a partir de preceitos finalísticos das medidas provisórias ${ }^{56}$.

Conforme os pressupostos já assinalados das medidas provisórias, as mesmas possuem como escopo a preservação do direito discutido na demanda, salvaguardando-o de quaisquer danos irreparáveis e preservam a utilidade da sentença, fazendo-a não se restar no vazio. Retirar a obrigatoriedade das medidas provisórias é prejudicar o

\footnotetext{
52 COUR PERMANENTE DE JUSTICE INTERnATIONALE, Comité Consultatif de juristes. ProcèsVerbaux des Séances du Comité - Avec Annexes. 1920, p. 609.

${ }^{53}$ COUR PERMANENTE DE JUSTICE INTERNATIONALE. Affaire des Zones franches de la HauteSavoie et du Pays de Gex. Série A/B - Arrêts, Ordonnances et avis Consultatifs. Fascicule n 46. 1932.

${ }^{54}$ PEREIRA, Op. Cit., p. 290.

55 COCATRE-ZILGIEN, André. Les mesures conservatoires décidées par le juge ou pa l'arbitre international. Revue Générale de Droit International Public - RGDIP, 1966, p. 46.

${ }^{56}$ MANI, V.S. Interim Measures of Protection: Article 41 of ICJ Statute and Article 94 of the UN Charter, Indian Journal of International Law - IJIL, vol. 10, 1970, p. 364.
} 
desenvolvimento regular das funções da Corte, pois impede de atingir o fim visado na sentença, tornando-a em vão.

Destarte, a carência de obrigatoriedade é contraditória com a natureza de Corte Judicial, essa qual, atua, em regra geral, através de decisões obrigatórias para os seus destinatários, excetuando os casos expressos em contrário, como a competência consultiva da CIJ, assim prevista no art. 96 da Carta das Nações Unidas ${ }^{57}$. Outrossim, a própria CPJI já se manifestou nesse sentido, ao arguir que: "seria incompatível com o seu Estatuto e com a sua posição como Tribunal de Justiça proferir uma sentença cuja validade ficasse subordinada à aprovação ulterior das partes" ${ }^{\prime 5}$.

Embora a manifestação supra da Corte ter sido direcionada às sentenças, entende-se que esse entendimento deve ser alargado às medidas provisórias, pois, conforme expressado, são instrumentos necessários à própria efetividade institucional e utilidade da sentença, sem a qual, criar-se-ia obstáculos para o exercício de poderes inerentes à natureza de órgão judicial.

Quanto a declaração da não obrigatoriedade dos despachados pela CPJI, de forma contrária ao fundamento assim utilizado pelos defensores da tese sobre essa característica, deve-se atentar às diversas perspectivas da obrigatoriedade, em peculiaridade, a relativa à vedação de antecipação da decisão.

Conforme colocado por CROCKETT, a interpretação da não obrigatoriedade inserta no julgado Affaire des Zones Franches deve ser dada a partir do conjunto estrutural da própria Corte, em especial, a sua natureza jurídica, a modo que não implique como restrição da eficiência de seus próprios atos, isto é, a carência de obrigatoriedade deve ser entendida como a ausência de força obrigatória do despacho em face da decisão final sobre o mérito ${ }^{59}$, não eximindo a vinculação da medida em face ao destinatário.

Destarte, até o caso LaGrand, a CIJ ainda não tinha se pronunciado de forma direta e explícita sobre a vinculação das medidas provisórias em face aos seus destinatários, e com a defesa dos EUA fundamentada na não vinculação, a Alemanha, em

\footnotetext{
${ }^{57}$ PEREIRA, Op. Cit., p. 296-297.

${ }^{58}$ COUR PERMANENTE DE JUSTICE INTERNATIONALE. Affaire des Zones Franches... 1932.

${ }^{59}$ CROCKETT, C.H. The Effects of Interim Measures of Protection in the International Court of Justice, California Western International Law Journal, vol. 7, 1977, p. 381-383.
} 
memoriais, levantou a tese da vinculação a partir do princípio da efetividade e da natureza jurídica $^{60}$, fato pelo qual, levou a corte a se pronunciar sobre a matéria.

Nesse sentido, a CIJ trabalhou em dois pontos para a determinação do caráter vinculativo das medidas provisórias, sejam eles, os trabalhos preparatórios e a Carta das Nações Unidas. Quanto aos trabalhos preparatórios do art. 41, entendeu-se que a escolha pela utilização do termo "ordem" fora dada pela ausência de meios de execução da Corte em face de suas decisões, contudo, a falta de meios de execução e a forma vinculativa não deveriam se confundir, dessa forma, não se restaria válido a construção dessa normativa como fundamento para afastar a vinculação ${ }^{61}$.

Quanto a Carta das Nações Unidas, fora analisado o art. 94, para assim compreender a acepção do termo "decisões" insertas no item n. ${ }^{\circ} 1$ e suas consequências. Nesse sentido, entendeu-se que, com a aplicação do termo decisão em sentido lato, afirmar-se-ia a natureza vinculativa das medidas provisórias por serem espécies de decisões; outrossim, mesmo com a restrição apenas às decisões definitivas, não seria motivo suficiente para negar a natureza vinculativa dessas medidas. Razões pelas quais, afirmou-se que as medidas provisórias possuem caráter vinculativo e criam obrigações legais ao seu destinatário ${ }^{62}$.

Outrossim, nos termos do art. 59 do Estatuto da CIJ, o efeito vinculativo da decisão da Corte será inter partes, isto é, será limitada às partes litigantes e a respeito do caso em questão, descartando-se os possíveis efeitos erga omnes ${ }^{63}$. Todavia, importante mencionar que, apesar da restrição a aplicação erga omnes, a decisão ainda poderá ter efeitos indiretos a terceiros em situações similares ${ }^{64}$, conforme assim verificado na decisão do caso Avena and Other Mexican Nationals ${ }^{65}$.

\footnotetext{
${ }^{60}$ INTERNATIONAL COURT OF JUSTICE. LaGrand Case (Germany v. United States of America), Memorial of the Federal Republic of Germany, Vol. 1, 1999, para. 4.121 e ss.

${ }^{61}$ INTERNATIONAL COURT OF JUSTICE. Reports of Judgments..., para. 107.

${ }^{62}$ Idem, para. 108-110.

${ }^{63}$ BAYLÓN, Juan de Dios Gutiérrez. La Corte Internacional de Juiticia al Terminar el Siglo. Anuario Mexicano de Derecho Internacional, vol. 1, 2001, p. 241.

${ }^{64}$ SHAW, Malcolm N. The International Court of Justice: a practical perspective. The International and Comparative Law Quarterly, Oxford, vol. 46, n. ${ }^{\circ}$ 4, Oct. 1997, p. 833.

${ }^{65}$ INTERNATIONAL COURT OF JUSTICE. Reports of Judgments, Advisory Opinions and Orders Case Concerning Avena and Other Mexican Nationals (Mexico V. United States Of America), 31 March 2004, para. 151.
} 


\section{CONCLUSÃO}

Diante o exposto no decorrer do presente estudo, pode-se perceber a existência de uma problemática acerca da efetividade das decisões da Corte Internacional de Justiça, pois, mesmo que se reconheça o caráter obrigatório das medidas provisórias, seus meios de implementação carecem de força substancial, remanescendo hipóteses de incumprimento sem quaisquer tipos de sanções.

Como se verificou na apreciação do caso LaGrand, o Estado Alemão fora capaz de preencher todos os elementos essenciais para a pronúncia de medidas provisórias por parte da Corte, quais sejam, a existência de competência e direito prima facie, urgência na necessidade da decisão e perigo de dano irreversível, assim percebidos através da existência do Protocolo Facultativo do TVRC, ofensa ao direito de comunicação consular e na iminência da execução da pena de morte de Walter LaGrand por parte dos Estados Unidos.

Todavia, apesar do preenchimento desses pressupostos e a consequência pronúncia por medidas provisórias, a respeito de suspender a execução de Walter LaGrand, a mesma se restou infrutífera, havendo seu descumprimento, e, posteriormente, com a fundamentação que a mesma sequer era obrigatória, pois tratar-se-ia de mera sugestão a ser adotada.

Fato pelo qual, originou a discussão acerca da obrigatoriedade dessas medidas, sendo essa reconhecida a partir de uma interpretação sistemática com a natureza da Corte como instituição jurisdicional, garantindo assim, o objeto de apreciação e utilidade das decisões. Apesar desse reconhecimento, apenas encontra-se o art. 94 da Carta das Nações Unidas como medida de efetivação, isto é, a partir da utilização do conceito lato de decisão/julgamento, pode-se requerer ao Conselho de Segurança da ONU medidas aplicáveis a compelir ao cumprimento, entretanto, há dificuldades desse meio diante a urgência existente em determinados casos, como assim verificado no caso LaGrand.

Depender tão somente do Conselho de Segurança como meio impositivo de aplicação das medidas provisórias em caso de descumprimento é obstaculizar o exercício da natureza de entidade judicial da Corte, pois não poderá proteger a utilidade das próprias decisões. Razões pelas quais, entende-se pela necessidade de implementação de vias 
diversas para atingir a efetivação das medidas provisórias, criando uma responsabilidade mais gravosa a situações de ocorrência de desobediência de tais ordens.

\section{REFERÊNCIAS}

BARROS, Napoleão Lucília. Soberania, Direitos Humanos e os Poderes de Pronúncia da Corte Internacional de Justiça a partir dos Casos LaGrand e Avena. Dissertação de Mestrado em Direito Internacional Público apresentada à Faculdade de Direito da Universidade de Coimbra. Coimbra. 2008.

BAYLÓN, Juan de Dios Gutiérrez. La Corte Internacional de Juiticia al Terminar el Siglo. Anuario Mexicano de Derecho Internacional, vol. 1, 2001.

BERNHARDT, Rudolf. Interim Measures Indicated by International Courts. Berlin; New York: Springer-Verlag, 1996.

BRIGGS, Hebert. La compétence incidente de la Cour internationale de Justice en tant que compétence obligatoire, Revue Générale de Droit International Public RGDIP, 1960.

COCATRE-ZILGIEN, André. Les mesures conservatoires décidées par le juge ou pa l'arbitre international. Revue Générale de Droit International Public - RGDIP, 1966.

COLLINS, Lauwrence. Provisional and Protective Measures in International Litigation, Recueil des Cours de l'Académie de Droit International - RCADI, vol. III, 1992.

COUR PERMANENTE DE JUSTICE INTERNATIONALE, Comité Consultatif de juristes. Procès-Verbaux des Séances du Comité - Avec Annexes. 1920.

COUR PERMANENTE DE JUSTICE INTERNATIONALE. Affaire des Zones franches de la Haute-Savoie et du Pays de Gex. Série A/B - Arrêts, Ordonnances et avis Consultatifs. Fascicule no 46. 1932.

CROCKETT, C.H. The Effects of Interim Measures of Protection in the International Court of Justice, California Western International Law Journal, vol. 7, 1977.

DANIELE, Luigi. Le Misure Cautelari nel Processo Dinanzi alla Corte Internazionale di Giustizia, Milano, Guiffré, 1993.

HAMBRO, Edvard. The Binding Character of Provisional Measures of Protection Indicated by the International Court of Justice, in Rechtsfragen der internationalen organization, Festschrift für Hans Wehberg zu seinem 70, Geburtstag, Herausgegeben von Walter Schatzel und Hans-Jürgen Schlochauer, Frankfur am Mai, Vitorio Klostermann, 1956.

HELLBECK, Eckhard. Provisional Measures of the International Court of Justice - Are They Binding Note, ASILS INT'L L.J., vol. 9, 1985.

HUSEK, Carlos Roberto. Curso de Direito Internacional Público, 14 a edição, São Paulo: LTr, 2017, p. 330-331.

INTERNATIONAL COURT OF JUSTICE. Application, Instituting Proceedings, LaGrand Case (Germany V. United States of America), 2 March 1999.

INTERNATIONAL COURT OF JUSTICE. LaGrand Case (Germany v. United States of America), Memorial of the Federal Republic of Germany, Vol. 1, 1999.

INTERNATIONAL COURT OF JUSTICE. LaGrand Case (Germany V. United States of America), Declaration of Judge Oda, 3 March 1999; INTERNATIONAL COURT OF JUSTICE. LaGrand Case (Germany V. United States of America), Declaration of Judge Schwebel, 3 March 1999; 
INTERNATIONAL COURT OF JUSTICE. Reports of Judgments, Advisory Opinions and Orders. LaGrand Case (Germany V. United States of America). Judgment Of 27 June 2001.

INTERNATIONAL COURT OF JUSTICE. Reports of Judgments, Advisory Opinions and Orders Case, Concerning Passage Through the Great Belt (Finland V. Denmark), Request for the Indication of Provisional Measures Order of 29 July 1991, 1991.

INTERNATIONAL COURT OF JUSTICE. Reports of Judgments, Advisory Opinions and Orders Case Concerning Avena and Other Mexican Nationals (Mexico V. United States Of America), 31 March 2004.

INTERNATIONAL COURT OF JUSTICE. Rules of Court (1978). Adopted on 14 april 1978 and entered into force on 1 july 1978. Disponível em: $<$ http://www.icjcij.org/en/rules>. 11 de março de 2018.

INTERNATIONAL COURT OF JUSTICE. Statute of The International Court of Justice. Disponível em: <http://www.icj-cij.org/en/statute>. 10 de março de 2018.

MACHADO, Jónatas E. M., Direito Internacional: Do paradigma clássico ao pós-11 de setembro, $3^{\circ}$ Edição, Coimbra: Coimbra Editora, 2006.

LABOUZ, Marie-Françoise. Affaire des Activités Militaires et Paramilitaires au Nicaragua et Contre Celui-Ci (Nicaragua c. Etats-Unis D'amérique): Ordonnance de la Cour Internationale de justice du 10 mai 1984 en indication de mesures conservatoires, Annuaire Français de Droit Internacional - AFDI, 1984.

MANI, V.S. Interim Measures of Protection: Article 41 of ICJ Statute and Article 94 of the UN Charter, Indian Journal of International Law - IJIL, vol. 10, 1970.

MENNECKE, Martin; TAMS, Christian. The Right to Consular Assistance Under International Law: The LaGrand Case Before the International Court of Justice, German Tearbook of International Law, vol. 42, 1999.

MIRON, Alina; SUZINEAU, Simon; FARCHAKH-FOURET, Loubna; CAICEDO, Jose Joaquin. La Cour Internationale de Justice. Revue Qudicoise de Droit International - RQDI, vol. 20.1, 2007.

MÜLLER, Daniel. Chronique de la CIJ. Revue Qudicoise de Droit International - RQDI, vol. 19.1, 2006.

PEREIRA, Maria de Assunção do Vale. As Medidas Provisórias na Jurisprudência Recente do Tribunal Internacional de Justiça. Boletim da Faculdade de Direito Universidade de Coimbra, STVDIA IVRIDICA 35, Coimbra: Coimbra Editora, 1998.

RUCZ, Claude. L'indication de mesures conservatoires par la Cour Internationale de Justice dans L'affaire des militaires et paramilitaires au Nicaragua et contre celi$c i$, Revue Générale de Droit International Public - RGDIP, 1985, n. ${ }^{\circ} 1$.

SHAW, Malcolm N. The International Court of Justice: a practical perspective. The International and Comparative Law Quarterly, Oxford, vol. 46, n. ${ }^{\circ}$ 4, Oct. 1997.

SZTUCKI, Jerzy. Interim Measures in the Hague Court: An Attempt at a Scrutiny. Deventer: Kluwer Law and Taxation Publishers, 1983.

TRILWAY, Hugh. The law and procedure of the Internaional Court of Justice, 19601989, 72, The British Yearbook of International Law (Mark. W. Janis, Carolyn Evans, eds.), The Hague, 1999.

UNITED NATIONS, Treaty Series, vol. 596, 2005.

VILLANI, Ugo. Tema di Indicazione di Misure Cautelari da Parte della Corte Internazionale di Giustizia, Rivista di Diritto Internazionale - RDI, vol. LVII. 